\title{
Measuring uncertainty: A streamlined application for the Ecuadorian economy
}

\author{
Guillermo Avellán ${ }^{1}$ • Manuel González-Astudillo2,3 \\ Juan José Salcedo $\mathrm{Cruz}^{4}$ (D)
}

Received: 6 August 2020 / Accepted: 8 May 2021 / Published online: 1 June 2021

(c) This is a U.S. government work and not under copyright protection in the U.S.; foreign copyright protection may apply 2021

\begin{abstract}
This paper develops a macroeconomic uncertainty index based on the multistage procedure that combines maximum likelihood and Bayesian estimation methods proposed by Jurado et al. (Am Econ Rev 105(3):1177-1216, 2015). Our approach streamlines the computation of the macroeconomic uncertainty index by specifying a state-space model estimated by maximum likelihood that allows us to obtain in one step the parameters of the model, the dynamic factors, and the forecast errors of the macroeconomic variables used to construct the index. Moreover, we estimate stochastic volatility models on the forecast errors also by maximum likelihood using a density filter that proves to be faster than a Bayesian estimation. After showing that our methodology produces reasonable results for the USA, we apply it to compute a macroeconomic uncertainty index for Ecuador, becoming the first index of this kind for a small developing or middle-income country. The results show that the Ecuadorian economy is more volatile and less predictable during recessions. We also provide evidence that macroe-
\end{abstract}

We thank Teresa Larreta and Mark Wilkinson for providing speedy and accurate research assistance. Two anonymous referees provided valuable feedback to improve a previous version of this paper.

M. González-Astudillo: The views expressed in this paper are solely the responsibility of the author and should not be interpreted as reflecting the views of the Board of Governors of the Federal Reserve System.

\anuel González-Astudillo

manuel.p.gonzalez-astudillo@frb.gov

Guillermo Avellán

gavell@uees.edu.ec

Juan José Salcedo Cruz

jjsalcedo@ecuadoreconomica.com

1 Universidad Espíritu Santo, Samborondón, Ecuador

2 Board of Governors of the Federal Reserve System, Washington, DC, USA

3 Facultad de Ciencias Sociales y Humanísticas, Escuela Superior Politècnica del Litoral, ESPOL, Guayaquil, Ecuador

4 Universidad Tecnológica Ecotec, Samborondón, Ecuador 
conomic uncertainty is detrimental to economic activity, finding that the responses of non-oil output, employment in the formal sector, and consumer prices to macroeconomic uncertainty shocks are sizable and persistent.

Keywords Macroeconomic uncertainty - State-space model $\cdot$ Stochastic volatility · Density filter

JEL Classification C32 · D80 - E32

\section{Introduction}

Uncertainty is a broad concept that frames several circumstances, whether they are economic related or not. For instance, there could be uncertainty episodes over the path of macro-level phenomena such as gross domestic product (GDP) growth, microlevel phenomena such as firms' hiring and investment decisions, and non-economicrelated events such as civil wars, climate change, and natural disasters. Uncertainty, then, can be a subjective term, and, as with any subjective concept, measuring it is challenging. Even when we narrow the term's scope into economic uncertainty, it is not an observable phenomenon and has to be inferred. To that end, the empirical literature has relied on proxies of uncertainty, using subjective concepts based on the volatility of stock market returns, dispersion of firms' profits, newspaper coverage, survey-based forecasts, and forecaster disagreement.

Jurado et al. (2015) (JLN hereafter) pioneered the development of an index of macroeconomic uncertainty for the USA. In JLN's framework, what matters for uncertainty is whether the economy has become more or less predictable through the lens of a forecasting model. Importantly, the index is as free as possible from theoretical models and dependence on a single observable economic indicator (e.g., stock market returns). Despite its relevance and usefulness, JLN's macroeconomic uncertainty index has barely been replicated in other economies (especially in developing countries), perhaps because of the lack of data or complications in implementing the procedure. In this paper, we streamline the procedure put forward by JLN to measure macroeconomic uncertainty and apply it to the Ecuadorian economy. Our intention is to offer a framework that can allow policymakers and researchers in general to construct and update a macroeconomic uncertainty index akin to that of JLN in a relatively timely and straightforward fashion.

To offer a clear understanding of our contribution, we recap the framework proposed by JLN. Their first step is to obtain, using the method of principal components, latent factors from a large data set that includes macroeconomic and financial variables, as well as latent factors from the series in the data set squared. The second step consists of estimating, by ordinary least squares, an autoregressive model for each of the macroeconomic variables in the data set augmented with the latent factors obtained in the first step. The third step involves estimating a stochastic volatility model with Bayesian methods on the regression residuals of the previous step and on those of the latent factors, assuming they have vector autoregressive (VAR) dynamics. The fourth step is to use the VAR structure of the macroeconomic variables and latent factors 
together to obtain the $h$-period-ahead forecast error variance of each variable, assuming a stochastic volatility process on the errors. The final step consists of obtaining an average or common factor of the square roots of the forecast error variances at different forecast horizons, which constitutes the macroeconomic uncertainty index.

Our framework offers two modifications to streamline the approach in JLN. First, by using a state-space model, we estimate by maximum likelihood-in a single stepthe latent factors, the coefficients of their VAR dynamics, and the coefficients of the regression used to forecast each of the macroeconomic series. Compared with JLN, this step allows us to gain efficiency in both achieving a smaller variance of the estimates and reducing computational time. Second, we obtain the one-step-ahead forecast errors from the state-space model in the previous step and estimate stochastic volatility models using maximum likelihood through a density filter. This step is computationally more economical than using Bayesian methods. The last two steps of the procedure are the same as in JLN. One additional feature to note is that by using the state-space formulation, one can update the forecast errors and then their volatilities, and the macroeconomic uncertainty index itself, as soon as new data arrive.

To compare our methodology with that of JLN, we use their same database and obtain the macroeconomic uncertainty indexes for the USA with our proposed approach. Our indexes have broadly similar statistical features compared with those in JLN, although somewhat higher because, to offer a more streamlined procedure within the state-space formulation of our model, we use a more parsimonious structure.

Confident that our methodology provides results consistent with our benchmark, we apply the proposed approach to obtain a macroeconomic uncertainty index for Ecuador, a small developing economy highly dependent on oil revenues. Our data set is much smaller than that of JLN, a common feature among developing countries. In total, we consider 24 variables that do not include financial indicators. Our macroeconomic uncertainty index tends to increase significantly before and during recessions and shares some of the JLN index features for the US economy regarding the role of predictors. For instance, the volatilities of the latent factors are important to explain macroeconomic uncertainty. Also, such factors help remove a portion of the forecastable component of the series, especially during recessions, permitting a cleaner measure of macroeconomic uncertainty.

In addition, we examine the effects of our measure of macroeconomic uncertainty on macroeconomic variables through local projections implemented with an instrumental variable (LP-IV) on our uncertainty index. The results show that an increase in uncertainty is detrimental to output and employment and pushes down prices. These results are similar to those obtained if we use the spread of sovereign bonds as our indicator of uncertainty, as it is usually done in developing countries.

This paper is organized as follows. Section 2 presents the related literature on the applications to compute macroeconomic uncertainty using the JLN framework. Section 3 describes the methodology proposed to construct the index. In Sect. 4, we describe the data sources and variables used. Section 5 presents the results of the macroeconomic uncertainty estimates for the USA and Ecuador and analyzes their properties, as well as the effect of uncertainty on Ecuadorian macroeconomic dynamics. Finally, Sect. 6 summarizes the main findings of the study. 


\section{Literature review}

This study constitutes the first application of JLN's framework to construct a macroeconomic uncertainty index in a small developing economy, such as Ecuador. To the best of our knowledge, the only applications for developed countries in the literature are Grimme and Stöckli (2018) for Germany and Shin et al. (2018) for South Korea. For larger developing economies, the only references are Huang et al. (2018) for China and Godeiro and Lima (2017) for Brazil. As can be seen, there is only a handful of applications of the JLN macroeconomic uncertainty index for other countries. We hope that our streamlined methodology can allow researchers in other countries to estimate a measure of uncertainty, such as that proposed by JLN.

In Latin America, the construction of Economic Policy Uncertainty (EPU) indexes following the newspaper-based method introduced by Baker et al. (2016) has gained traction over the recent past. Countries such as Brazil, Chile, Colombia, Ecuador, and Mexico already have at least one application of the EPU Index. ${ }^{1}$ However, the EPU is conceptually very different to the index of macroeconomic uncertainty proposed by JLN, which is the objective of our paper.

For instance, Grimme and Stöckli (2018) shows that the EPU index for Germany is more volatile and overestimates uncertainty compared with the JLN's macroeconomic index, as the former reacts quicker to bad news events than the latter. In fact, the uncertainty index obtained by Grimme and Stöckli is less volatile than commonly used indicators, such as the Expected Stock Market Volatility (VDAX), which is the German equivalent of the US VIX. Importantly, the authors find that macroeconomic uncertainty can explain $11 \%$ of the change in Germany's investment. Their index also reported a significant increase during the financial crisis in 2008, while a downward trend is experienced during the European sovereign debt crises.

Shin et al. (2018) estimate the JLN uncertainty index for South Korea, which has similar dynamics with the Korean analog of the US VIX (denominated VKOSPI), but not with the EPU index. Regarding the effect of macroeconomic uncertainty on economic activity, the Korean indicator of industrial production falls sharply about $1 \%$ when uncertainty increases. Compared with the effect of the other two indexes (VKOSPI and EPU), the effect of macroeconomic uncertainty is more pronounced in the short run.

For China, Huang et al. (2018) compute the JLN macroeconomic uncertainty index and investigate if there are spillovers with the USA. The results show that the Chinese index reacts significantly to uncertainty increases in the USA, but that the effect in the opposite direction is not significant. In addition, both the Chinese and the US indexes have effects on China's real economy.

Godeiro and Lima (2017) estimate the JLN macroeconomic index for Brazil and show that the level of uncertainty rises during recessions, but there are also rises in uncertainty that do not precede a recession. Additionally, they find that an increase in uncertainty is detrimental to industrial production and employment only when the forecasting horizon is 12 months.

\footnotetext{
${ }^{1}$ Padilla (2019) is the only application of the EPU index for Ecuador. Further details on the EPU are available at http://www.policyuncertainty.com.
} 


\section{Methodology}

Our modeling strategy relies on the framework developed by JLN, and we use their notation to facilitate the comparison with our approach. There are two fundamental differences in how we implement JLN's proposal. First, we estimate a dynamic factor model (DFM) by maximum likelihood using the expectations maximization (EM) algorithm (see Watson and Engle 1983; Banbura and Modugno 2014, for example) which allows us to gain efficiency compared with the two-step estimator in JLN. Second, we estimate the stochastic volatility processes by maximum likelihood by using a density filter, as in Friedman and Harris (1998) and Kawakatsu (2007), instead of the Bayesian estimation used by JLN, which allows us to implement a more streamlined and expedited coding strategy. ${ }^{2}$

\subsection{Modeling macroeconomic uncertainty}

We are interested in the $h$-period-ahead uncertainty of each variable $y_{j t} \in Y_{t}=$ $\left(y_{1 t}, y_{2 t}, \ldots, y_{N_{Y} t}\right)^{\prime}$ denoted by $\mathscr{U}_{j t}^{y}(h)$. This uncertainty represents the conditional volatility of the purely unforecastable component of the future value of the series, as follows:

$$
\mathscr{U}_{j t}^{y}(h) \equiv \sqrt{E\left(\left(y_{j, t+h}-E\left(y_{j, t+h} \mid I_{t}\right)\right)^{2} \mid I_{t}\right)},
$$

where we assume that the economic agents use all the information available at time $t$, denoted as $I_{t}$.

Under this definition, the measure of macroeconomic uncertainty is constructed by aggregating the individual uncertainties at each date, $\mathscr{U}_{j t}^{y}(h)$, using aggregation weights, $w_{j}$, as follows:

$$
\mathscr{U}_{t}^{y}(h) \equiv \operatorname{plim}_{N_{y} \rightarrow \infty} \sum_{j=1}^{N_{y}} w_{j} \mathscr{U}_{j t}^{y}(h) \equiv E_{w}\left[\mathscr{U}_{j t}^{y}(h)\right] .
$$

To implement the estimation of this model, we replace the conditional expectation $E\left(y_{j, t+h} \mid I_{t}\right)$ in (1) with a forecast obtained from a medium-rich model (from here on we use $E_{t} y_{j, t+h}$ instead of $E\left(y_{j, t+h} \mid I_{t}\right)$ for notational convenience). This forecast allows us to obtain the forecast error for each variable, which, in turn, forms the basis of the uncertainty measures. The medium-rich model includes autoregressive components as well as common factors obtained from the macroeconomic variables

\footnotetext{
${ }^{2}$ As is prevalent in small developing economies due to data availability, in this setup we deal only with a set of macroeconomic variables from which we obtain both the dynamic factors and the macroeconomic uncertainty index. In contrast, JLN dealt with two sets (macroeconomic and financial), excluding the set of financial variables from the uncertainty index's construction. Our approach is readily able to include financial variables as well.
} 
and is given by the following specification:

$$
y_{j t}=\phi_{j}(L) y_{j, t-1}+\Lambda_{j}^{Y F} \hat{F}_{t}+\Lambda_{j}^{Y G} \hat{G}_{t}+v_{j t}^{y},
$$

where $\phi_{j}(L)$ is a lag polynomial of order 4 in the lag operator, $L, \Lambda_{j}^{Y F}$, and $\Lambda_{j}^{Y G}$ are coefficient vectors of dimension $1 \times N_{F}$ and $1 \times N_{G}$, respectively. $\hat{F}_{t}$ is a $N_{F} \times 1$ vector that contains the consistent estimators of the common factors for $Y_{t}$ and $\hat{G}_{t}$, of dimension $N_{G} \times 1$, contains consistent estimators of the common factors for the variables in $Y_{t}$ squared (denoted $Y_{t}^{s}$ ).

Notice that we do not incorporate lags or leads of the common factors. Following Giannone et al. (2008) and Giannone et al. (2010), we consider only contemporaneous factors, which in turn follow a vector autoregressive structure. In any case, the setup that we propose is flexible enough to allow one to include lags or leads of the common factors. In addition, as opposed to JLN, we do not incorporate the square of the first factor of the series in levels $\left(\hat{F}_{1 t}^{2}\right)$, so that the state-space model can remain linear.

In order to estimate the macroeconomic uncertainty index, we first estimate the model in Eq. (3) to obtain the forecast errors, which are the basis for the uncertainty index through their estimated volatility, as indicated previously. The next two sections lay out the estimation strategy.

\subsection{Estimation of the forecasting model and the forecast errors}

We estimate jointly the coefficients and the factors in (3) using the following statespace representation (notice the identity $Y_{t}=X_{t}$ ):

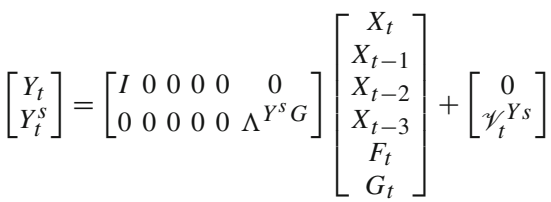

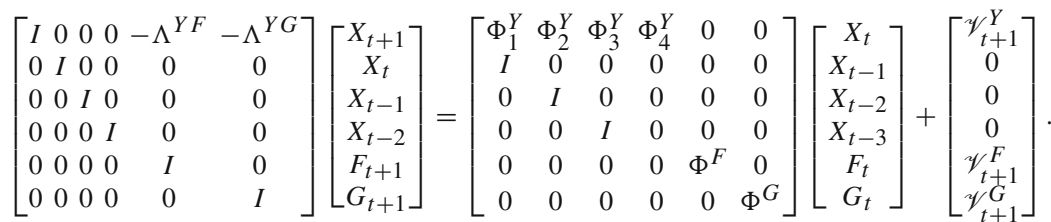

In the model of Eqs. (4)-(5), $\Lambda^{Y F}$ and $\Lambda^{Y G}$ are the factor loadings $\left(N_{Y} \times N_{F}\right.$ and $N_{Y} \times N_{G}$, respectively) of the observable macroeconomic variables, $Y_{t}$, on the common factors, $F_{t}$ and $G_{t}$, whereas $\Lambda^{Y^{s} G}\left(N_{Y} \times N_{G}\right)$ contains the loading coefficients of the variables squared, $Y_{t}^{s}$, on their common factors, $G_{t}$. The $N_{Y} \times N_{Y}$ matrices $\Phi_{l}^{Y}, l=1,2,3,4$ are diagonal and contain the autoregressive coefficients of the observable variables, whereas the respective $N_{F} \times N_{F}$ and $N_{G} \times N_{G}$ matrices $\Phi^{F}$ and $\Phi^{G}$ contain the vector autoregressive coefficients of the factors. ${ }^{3}$

\footnotetext{
3 We have assumed a first-order autoregressive structure in the factors for expositional purposes.
} 
Additionally, each of the elements in the vectors $\mathscr{V}_{t}^{K}, K=Y, F, G$ contains stochastic volatility dynamics, as follows:

$$
\begin{aligned}
v_{j t} & =\sigma_{j t} u_{j t}, \\
& =\exp \left(\frac{1}{2}\left(\alpha_{0 j}+\alpha_{1 j} z_{j t}\right)\right) u_{j t}, \\
z_{j, t+1} & =\rho_{j} z_{j t}+\sqrt{\left(1-\rho_{j}^{2}\right)} e_{j, t+1},
\end{aligned}
$$

for $j=1,2, \ldots, N_{Y}+N_{F}+N_{G}$, where $u_{j t}$ and $e_{j, t+1}$ are independent $N(0,1)$ both across time and variables, $\log \left(\sigma_{j t}^{2}\right)=\alpha_{0 j}+\alpha_{1 j} z_{j t}, \alpha_{1 j}>0$, and $\left|\rho_{j}\right|<1$.

We estimate the model in Eqs. (4)-(5) (without taking into account stochastic volatility) by maximum likelihood using the EM algorithm. In this way, we gain efficiency compared with the estimation in JLN because the estimation obtains the loading and autoregressive coefficients as well as the latent factors in one step.

Notice that we can write equation (5) as follows:

$$
\mathscr{X}_{t+1}=\Phi^{\mathscr{X}} \mathscr{X}_{t}+\mathscr{V}_{t+1}^{\mathscr{X}},
$$

where $\mathscr{X}_{t}=\left(X_{t}, X_{t-1}, X_{t-2}, X_{t-3}, F_{t}, G_{t}\right)^{\prime}, \mathscr{V}_{t}^{\mathscr{X}}=\left(\mathscr{V}_{t}^{Y}, 0,0,0, \mathscr{V}_{t}^{F}, \mathscr{V}_{t}^{G}\right)^{\prime}$, and $\Phi^{\mathscr{X}}$ is a conformable matrix. Hence, the optimal $h$-period-ahead forecast is given by the conditional mean

$$
E_{t} \mathscr{X}_{t+h}=\left(\Phi^{\mathscr{X}}\right)^{h} \mathscr{X}_{t}
$$

with $h$-period-ahead forecast error variance given by

$$
\Omega_{t}^{\mathscr{X}}(h)=E_{t}\left[\left(\mathscr{X}_{t+h}-E_{t} \mathscr{X}_{t+h}\right)\left(\mathscr{X}_{t+h}-E_{t} \mathscr{X}_{t+h}\right)^{\prime}\right] .
$$

For $h=1$, the forecast error variance is

$$
\Omega_{t}^{\mathscr{X}}(1)=E_{t}\left(\mathscr{V}_{t+1}^{\mathscr{X}} \mathscr{V}_{t+1}^{\mathscr{X}^{\prime}}\right)
$$

whereas for $h>1$ it is

$$
\Omega_{t}^{\mathscr{X}}(h)=\Phi^{\mathscr{X}} \Omega_{t}^{\mathscr{X}}(h-1) \Phi^{\mathscr{X}^{\prime}}+E_{t}\left(\mathscr{V}_{t+h}^{\mathscr{X}} \mathscr{V}_{t+h}^{\mathscr{X}^{\prime}}\right)
$$

To obtain the expected forecast uncertainty of variable $y_{j t}$ given information at time $t$, previously denoted as $\mathscr{U}_{j t}^{y}(h)$, we use a selection vector, $1_{j}$, and take the square root of the appropriate entry of the forecast error variance $\Omega_{t}^{\mathscr{X}}(h)$, as follows: 


$$
\mathscr{U}_{j t}^{y}(h)=\sqrt{1_{j}^{\prime} \Omega_{t}^{\mathscr{X}}(h) 1_{j}} .
$$

As indicated in Eq. (2), we aggregate the individual uncertainty estimates in (14) using weights $w_{j}$ to estimate the macroeconomic uncertainty index. In our case, as in the baseline version of JLN, we use uniform weights $\left(w_{j}=1 / N_{Y}\right)$, and consequently the aggregation is a simple average of the individual uncertainties. ${ }^{4}$

We emphasize that the time variation in the $h$-period-ahead forecast error variance, $\Omega_{t}^{\mathscr{X}}(h)$ —and hence in the expected forecast uncertainty of each variable $j, \mathscr{U}_{j t}^{y}(h)$ occurs because of the presence of stochastic volatility in the errors $\mathscr{V}_{t}^{\mathscr{X}}$. In the next section, we propose how to estimate the stochastic volatility processes.

\subsection{Estimating the stochastic volatility processes}

We estimate the stochastic volatility model in Eqs. (6)-(8) by maximum likelihood, using a density filter with numerical integration to obtain the likelihood function.

We first obtain the filtered disturbances of $\mathscr{V}_{t}^{Y}$ and the smoothed disturbances of $\mathscr{V}_{t}^{F}$ and $\mathscr{V}_{t}^{G}$ by using the forward and backward recursions, respectively, of the Kalman filter and smoother once the state-space model in Eqs. (4)-(5) is estimated as described in the previous section.

The density filter works as follows (we omit the subscript $j$ for convenience of notation, but this description applies to each error of the variables with which the macroeconomic uncertainty index will be constructed, $y_{j t}$, as well as the common factors $F_{t}$ and $G_{t}$ ):

$$
\begin{aligned}
p\left(z_{t} \mid \mathfrak{F}_{t-1}\right) & =\int p\left(z_{t} \mid z_{t-1}\right) p\left(z_{t-1} \mid \mathfrak{F}_{t-1}\right) \mathrm{d} z_{t-1}, \quad \text { prediction step } \\
p\left(z_{t} \mid \mathfrak{F}_{t}\right) & =\frac{p\left(v_{t} \mid z_{t}\right) p\left(z_{t} \mid \mathfrak{F}_{t-1}\right)}{c_{t}}, \quad \text { updating step } \\
c_{t} & =\int p\left(v_{t} \mid z_{t}\right) p\left(z_{t} \mid \mathfrak{F}_{t-1}\right) \mathrm{d} z_{t} \\
\mathfrak{L}(\theta) & =\sum_{t=1}^{T} \ln c_{t}, \quad \text { likelihood function }
\end{aligned}
$$

where $\theta=\left\{\alpha_{0}, \alpha_{1} \rho\right\}$ and $\mathfrak{F}_{t}$ is the $\sigma$-field with the information spanned by the sequence $\left\{v_{s}\right\}_{s=1}^{t}$. Notice that the filtered state entering the stochastic volatility process can be obtained by calculating $E\left(z_{t} \mid \mathfrak{F}_{t}\right)=\int z_{t} p\left(z_{t} \mid \mathfrak{F}_{t}\right) \mathrm{d} z_{t}$.

\footnotetext{
4 In JLN, the factors were obtained from a larger information set that included financial in addition to macroeconomic variables, but the macroeconomic uncertainty index was obtained only from macroeconomic variables. The setup presented in this paper is able to accommodate that possibility by including the additional financial variables in the set of observable variables of the state-space in Eqs. (6)-(8) and by then choosing the desired macroeconomic variables with the appropriate selection vector, $1_{j}$.
} 
We use the Gauss-Legendre quadrature to approximate the above integrals, as follows:

$$
\int_{a}^{b} f(\tilde{z}) \mathrm{d} \tilde{z} \approx \sum_{i=1}^{m} w_{i} f\left(\tilde{z}_{i}\right)
$$

where $w_{i}$ and $\tilde{z}_{i}$ are the weights and nodes, respectively, of the quadrature and $w(\tilde{z})=$ 1. "Appendix B" describes the density filter in more detail.

We can get each of the elements in $E_{t}\left(\mathscr{V}_{t+h}^{\mathscr{X}} \mathscr{V}_{t+h}^{\mathscr{X}} \mathscr{X}^{\prime}\right)$ to compute the $h$-period-ahead forecast error variance in Eqs. (12) and (13) as follows (once again, we omit the subscript $j$ for notational convenience): Given that $v_{t+h}=\sigma_{t+h} u_{t+h}$ and the normality and independence assumptions of the innovations $u_{t}$ and $e_{t}$, then

$$
\begin{aligned}
E_{t} v_{t+h}^{2} & =E_{t} \sigma_{t+h}^{2}, \\
& =E_{t} \exp \left(\alpha_{0}+\alpha_{1} z_{t+h}\right), \\
& =\exp \left(\alpha_{0}+\alpha_{1} E_{t} z_{t+h}+\frac{1}{2} \alpha_{1}^{2} \operatorname{var}_{t} z_{t+h}\right), \\
& =\exp \left(\alpha_{0}+\alpha_{1} \rho^{h} z_{t}+\frac{1}{2} \alpha_{1}^{2}\left(1-\rho^{2}\right) \sum_{s=0}^{h-1} \rho^{2 s}\right),
\end{aligned}
$$

where we use the one-sided estimate, $E\left(z_{t} \mid \mathfrak{F}_{t}\right)$, in place of $z_{t}$.

\section{Data}

This section describes the variables used and the sample as well as the selection of the number of factors of the DFM used to forecast.

\subsection{Variables and sample}

To construct the uncertainty index, we rely on available monthly information from official sources, such as the Central Bank of Ecuador (BCE), the National Institute of Statistics and Census (INEC), and the Internal Revenue Service (SRI).

The selected variables reflect the macroeconomic activity of the country and are frequently updated. These variables are based on the data set collected by GonzálezAstudillo and Baquero (2019) for their nowcasting model for Ecuador's real GDP growth rate. All in all, we use 24 variables grouped into six categories: (i) banking and monetary sector, (ii) international trade, (iii) prices and confidence indexes, (iv) real sectoral indexes, (v) government finances, and (vi) labor market indexes. "Appendix A" describes the data in more detail.

Given the availability of data, we use a semi-balanced data set that starts in January 2004 and ends in December 2019 to estimate the model, but we obtain the macroeconomic uncertainty index through June 2020 with the data released until then. Where 
needed, we seasonally adjust the series using the X-12 ARIMA multiplicative decomposition method.

\subsection{Determining the number of factors}

Following JLN, we employ the statistical procedure proposed by Bai and Ng (2002) that provides accurate results for a sample with a large number of variables and that has good finite-sample properties. When we test for a consistent number of factors constrained to a maximum of 10 , the test suggests using only one factor. Based on these results, the number of both linear (level) and nonlinear (squared) factors is one each. ${ }^{5}$

\section{Results}

This section lays out the results of our proposed methodology, first comparing its findings with the results of JLN and then applying it to find a macroeconomic uncertainty index for Ecuador.

\subsection{Comparing our procedure with JLN's methodology}

The first step to evaluate our procedure is to compare its results with those of JLN. In this section, we compare the indexes for $h=1,3$, and 12 along various statistical dimensions.

We use the same sample and variables as in JLN and compute the macroeconomic uncertainty indexes following our methodology. Figure 1a shows our results, and Fig. $1 \mathrm{~b}$ reproduces the results in JLN. As can be seen, the dynamics are very similar across forecast horizons. However, there is a difference in the level of the series, with our indexes being higher than those of JLN. In any case, the qualitative features of the indexes are similar. For instance, the average uncertainty increases with the forecasting horizon and our indexes tend to surpass the 1.65 standard deviation threshold during the same recession periods as in JLN.

In Table 1, we compute key summary statistics for each macroeconomic index in both JLN and our paper. In general, the indexes in our paper share the features of those in JLN. For example, the correlations (contemporaneous and lagged) with industrial production (IP) are relatively similar. Additionally, the asymmetry of the distributions of our indexes is broadly similar to that of the indexes in JLN, but theirs have slightly fatter tails than ours. There are also some differences. For instance, even though our indexes are very persistent, the first autocorrelation coefficients are slightly smaller

\footnotetext{
5 The Cattell (1966) test suggests four factors. The macroeconomic uncertainty index constructed with this number of factors is similar to that obtained with only one factor. We need to remember that JLN discarded the explanatory variables that did not pass a stringent test of statistical significance, which is not performed in our procedure. For that reason, including more factors could lead to overfitting.
} 


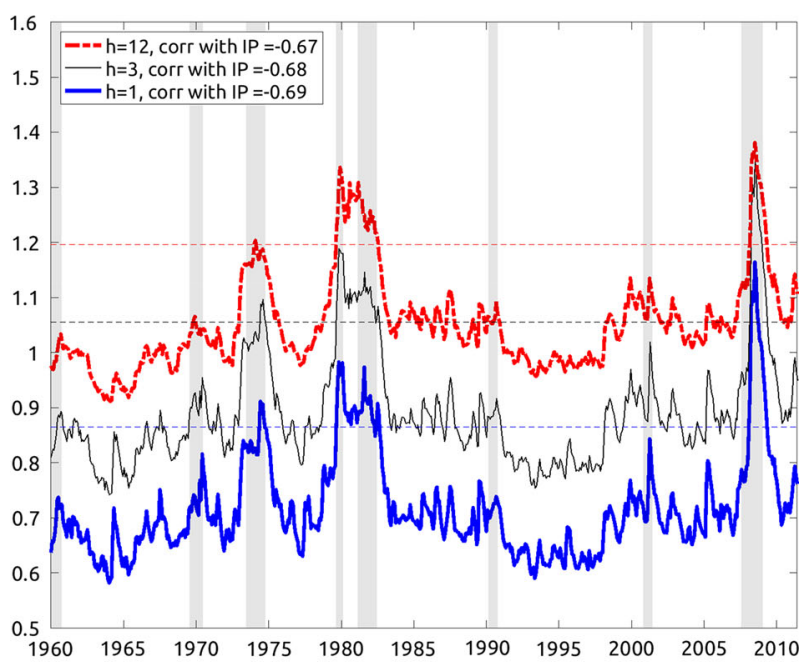

(a) This paper

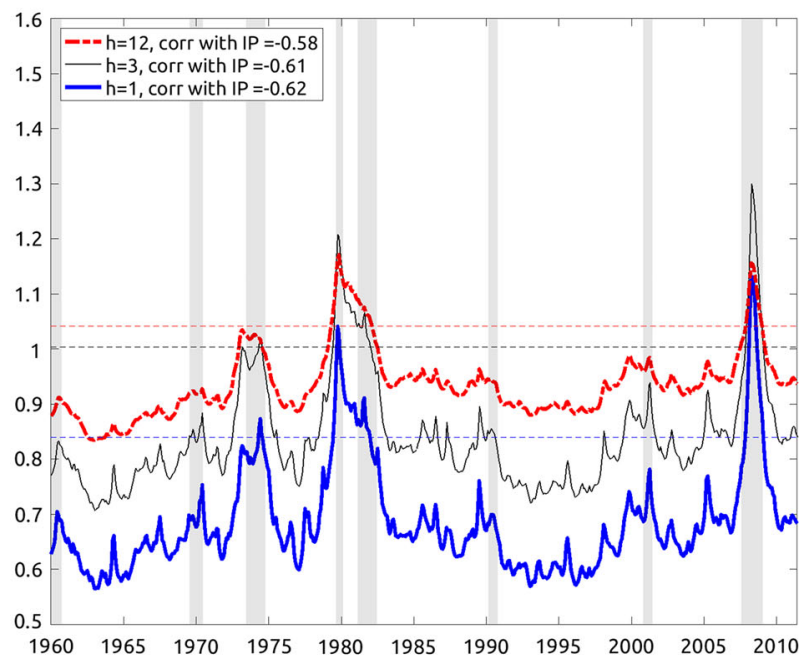

(b) JLN

Fig. 1 Macroeconomic uncertainty indexes. Note: The horizontal lines correspond to 1.65 standard deviations above the mean of each index. Shaded areas correspond to NBER recession periods

than those in JLN, and our half lives are shorter. ${ }^{6}$ Moreover, the results indicate that the JLN uncertainty indexes around 5 months earlier tend to correlate the most with IP, whereas in our case, that happens only around 2 months earlier.

\footnotetext{
${ }^{6}$ One possible reason for the lower persistence in our indexes is that we use the one-sided stochastic volatility estimate from our density filter as opposed to the two-sided estimate from the Bayesian estimation in JLN, which would be smoother and more persistent.
} 
Table 1 JLN versus this paper: summary statistics

\begin{tabular}{|c|c|c|c|c|c|c|}
\hline & \multicolumn{3}{|l|}{ JLN } & \multicolumn{3}{|c|}{ This paper } \\
\hline & $\overline{\mathscr{U}}_{t}^{y}(1)$ & $\overline{\mathscr{U}}_{t}^{y}(3)$ & $\overline{\overline{\mathscr{U}}_{t}^{y}(12)}$ & $\overline{\mathscr{U}}_{t}^{y}(1)$ & $\overline{\mathscr{U}}_{t}^{y}(3)$ & $\overline{\mathscr{U}}_{t}^{y}(12)$ \\
\hline $\operatorname{AR}(1)$ & 0.99 & 0.99 & 0.99 & 0.97 & 0.98 & 0.98 \\
\hline Half life & 50.28 & 65.95 & 123.22 & 22.11 & 30.33 & 42.78 \\
\hline Skewness & 1.81 & 1.74 & 1.30 & 1.70 & 1.57 & 1.35 \\
\hline Kurtosis & 7.06 & 6.60 & 4.97 & 6.72 & 5.96 & 4.90 \\
\hline IP-corr $(0)$ & -0.62 & -0.61 & -0.58 & -0.69 & -0.68 & -0.67 \\
\hline IP-corr(12) & -0.49 & -0.52 & -0.57 & -0.34 & -0.37 & -0.44 \\
\hline IP-corr $(-12)$ & -0.15 & -0.14 & -0.16 & -0.24 & -0.24 & -0.27 \\
\hline $\max$ IP-corr(k), $k>0$ & -0.70 & -0.70 & -0.67 & -0.70 & -0.70 & -0.69 \\
\hline At lag $k=$ & 4 & 5 & 5 & 2 & 2 & 2 \\
\hline $\max \operatorname{IP}-\operatorname{corr}(\mathrm{k}), k<0$ & -0.59 & -0.58 & -0.55 & -0.68 & -0.67 & -0.65 \\
\hline At lag $k=$ & -1 & -1 & -1 & -1 & -1 & -1 \\
\hline
\end{tabular}

Table 2 JLN versus this paper: differences

\begin{tabular}{|c|c|c|c|c|c|}
\hline \multicolumn{3}{|c|}{ Correlation coefficient } & \multicolumn{3}{|c|}{$\underline{\text { Standardized mean difference }}$} \\
\hline$\overline{\bar{U}}_{t}^{y}(1)$ & $\overline{\mathscr{U}}_{t}^{y}(3)$ & $\overline{\overline{\mathscr{U}}_{t}^{y}(12)}$ & $\overline{\mathscr{U}}_{t}^{y}(1)$ & $\overline{\mathscr{U}}_{t}^{y}(3)$ & $\overline{\mathscr{U}}_{t}^{y}(12)$ \\
\hline 0.9386 & 0.9332 & 0.9357 & 0.3342 & 0.5152 & 1.8489 \\
\hline
\end{tabular}

Finally, we present the pairwise correlation coefficients between each of the indexes in JLN and our paper, as well as the standardized average difference between them in Table 2. As can be seen, the correlation coefficients for all the indexes are greater than 0.93 , indicating a great degree of co-movement between our indexes and those in JLN. However, as evidenced in Fig. 1, our indexes indicate a somewhat higher degree of macroeconomic uncertainty. In fact, our indexes are roughly within 0.3 and 1.8 standard deviations of the indexes obtained by JLN, on average.

There could be several reasons for the differences between the results from our approach and those of JLN. For instance, we do not consider the first linear factor squared in the set of explanatory variables to obtain the forecast errors. Neither do we include lags of the factors. One could expect that these additional explanatory variables reduce the variability of the forecast errors. ${ }^{7}$ Another possibility is that our more efficient estimation method simply weighs differently the factors to obtain the forecast errors. In any case, we emphasize that our streamlined procedure obtains results very close to those in JLN and could be used to approximate reasonably well their uncertainty measure and to update it swiftly.

\footnotetext{
${ }^{7}$ As pointed out before, we could actually include lags of the factors in our state-space model structure at the cost of increasing its dimension and overfitting. In that case, with two lags in the factors, the standardized mean difference between our approach and that of JLN is close to 0 for $h=1$ and 3 and about 0.7 for $h=12$.
} 


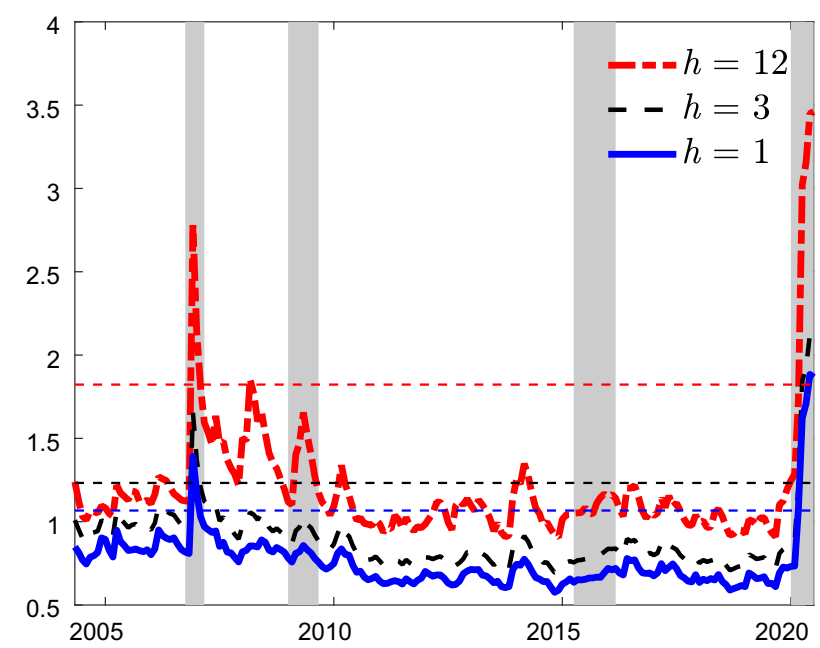

Fig. 2 Aggregate uncertainty for $h=1,3$ and 12. Note: The horizontal lines correspond to 1.65 standard deviations above the mean of each index. Shaded areas correspond to recession periods defined as two or more consecutive quarters of declining GDP

\subsection{The indexes for Ecuador}

Using our methodology, we estimate the macroeconomic uncertainty index for three horizons: $h=1,3$, and 12 months for the Ecuadorian economy. Figure 2 plots the macroeconomic uncertainty indexes for these three horizons, including recession bars based on official data from the BCE. ${ }^{8}$ This figure includes dashed horizontal lines to represent 1.65 standard deviations above the mean for each horizon as a benchmark measure of high uncertainty. ${ }^{9}$

The figure shows that, on average, the level of uncertainty increases with the horizon length. Additionally, uncertainty increases during the four recessions in the sample, but there are rises in uncertainty that do not necessarily precede a recession. The behaviors of uncertainty for all the horizons are quite similar. For example, the estimates of macroeconomic uncertainty exceed 1.65 standard deviations over its mean twice in the sample: during the 2006-07 recession and the coronavirus disease (COVID-19) crisis. ${ }^{10}$ We group the increases of uncertainty into the four recessionary episodes of the sample.

The first episode of high uncertainty occurs between October 2006 and March 2007, during the elections that eventually made Rafael Correa president. The variables

\footnotetext{
8 Table 5 in "Appendix C" shows additional results regarding our forecasting regressions such as the coefficient of determination of the individual regressions and the average individual uncertainties for $h=1$.

9 We also computed the macroeconomic uncertainty indexes using principal components analysis and found that they are very similar to those obtained from averaging the individual uncertainties-our baseline. The main advantage of the latter is that it does not require a balanced panel to obtain the common component (macroeconomic uncertainty index) as is the case with the former.

10 The 12-month-ahead index slightly exceeds the threshold one more time in February 2008, at the beginning of the Great Recession.
} 
that experience the highest levels of uncertainty are the employment indexes in the construction and services sectors.

The second episode occurs from early 2008 through mid-2009. This period coincides with the country's sovereign debt default and the subsequent recession triggered by the fall in oil prices that, in turn, led to lower oil exports and government oil revenues. During this period, the variable that experiences the highest level of uncertainty is the value-added tax receipts for the 1-month-ahead and 3-month-ahead indexes. In the 12month-ahead index, the labor market index for the services sector reports the highest level of uncertainty. After this episode, macroeconomic uncertainty starts declining relative to its previous levels.

During the third episode, between April 2015 and March 2016, demand deposits and near money experience the highest levels of uncertainties for the 1-month-ahead index. Meanwhile, the employment index of the services sector reports the highest level of uncertainty for the 3-month-ahead and 12-month-ahead indexes. This period of high uncertainty occurs roughly at the same time of considerable declines in oil prices between late 2014 and early 2016.

Finally, the fourth episode occurs at the end of the sample because of the COVID19 crisis. In April 2020, the collapse of oil prices to negative $\$ 37.63$ per barrel and Ecuador's oil pipelines rupture deepened the country's fiscal crisis and resulted in an external debt restructuring. As a consequence, the variables that experience the highest levels of uncertainties are oil production and the activity index on commerce. As can be seen, increases in the indexes of macroeconomic uncertainty coincide frequently with swings in oil prices. ${ }^{11}$

As defined by JLN, our indexes reflect the volatility of the unforecastable component across many series. Therefore, each series can be affected by its own uncertainty shocks as well as by external macroeconomic uncertainty shocks. To estimate the influence of macroeconomic uncertainty across all series composing the index, we regress the uncertainty of each of the 24 variables on the aggregate macroeconomic uncertainty index for the three horizons. These regressions enable us to compute the following coefficient of determination, $R_{j \tau}^{2}(h)$, for each series:

$$
R_{j \tau}^{2}(h)=\frac{\operatorname{var}_{\tau}\left(\hat{\varphi}_{j \tau}(h) \overline{\mathscr{U}}_{t}^{y}(h)\right)}{\operatorname{var}_{\tau}\left(\hat{\mathscr{U}}_{j t}^{y}(h)\right)},
$$

where $\hat{\varphi}_{j \tau}(h)$ is the coefficient from a regression of individual uncertainty, $\hat{\mathscr{U}}_{j t}^{y}(h)$, on macroeconomic uncertainty, $\overline{\mathscr{U}}_{t}^{y}(h)$. Similar to JLN, this statistic is estimated for $h=$ 1,3 , and 12 months for the full sample, for recession periods, and for non-recessionary periods. Then, we obtain the average $R^{2}$ from the regressions of individual uncertainty on macroeconomic uncertainty for the three horizons under each scenario, denoted as $R_{\tau}^{2}(h)$. In this context, $R_{\tau}^{2}(h)$ represents the fraction of total uncertainty that can be explained by macroeconomic uncertainty - the explanatory power of macroeconomic uncertainty increases as $R_{\tau}^{2}(h)$ rises.

\footnotetext{
11 The Ecuadorian economy has been historically influenced by fluctuations in oil revenues (see World Bank Group 2018; García-Albán et al. 2020).
} 
Table 3 indicates that the forecasting ability of our macroeconomic uncertainty index increases with the horizon length. Moreover, similar to the findings in JLN, our index has, on average, a higher explanatory power during recessions than for the full-sample and non-recessionary periods. In our case, the explanatory power of macroeconomic uncertainty during recessions is larger than the results obtained by JLN for the USA. However, we must judge these results cautiously because our sample comprises only four recession periods.

It is also important to highlight that there is substantial variation in the explanatory power of macroeconomic uncertainty among the series composing our index. For example, when the forecast horizon is $h=3, R_{\tau}^{2}(h)=0.32$ for the full sample. However, based on further research not presented in Table 3, this estimate ranges from a level close to 0 for the Current Situation Index to 0.81 for the activity index on manufacturing. ${ }^{12}$

\subsection{The role of the predictors}

The two factors, $F_{t}$ and $G_{t}$, allow the model to remove some of the predictable components for each variable. We evaluate the importance of these predictable variations in our estimates by analyzing the uncertainties of the two factors, which contribute to the $h$-period-ahead uncertainty of each variable. Figure 3 plots the one-period-ahead uncertainty for each of the two factors. The degree of fluctuations in their uncertainties suggests that the factors contribute significantly to explain each macroeconomic variable's uncertainty to be forecast.

The inclusion of these latent factors can substantially affect the individual uncertainty series' level and behavior. As mentioned before, traditional measures of uncertainty most often neglect these latent components. We examine the contribution of these factors by first re-estimating the individual uncertainty series, removing only the unconditional mean of the variables, with a model as follows:

$$
y_{j t}=\tilde{\sigma}_{j t} \tilde{u}_{j t} .
$$

This vanilla model, potentially misspecified, neglects the role of serial correlation in each of the variables as well as the estimated factors as predictors in the multivariate forecasting regression of $y_{i, t+h} \cdot{ }^{13}$ Figure 4 plots the one-period-ahead uncertainty index using this possibly misspecified model and compares it with the baseline case that uses the full set of predictors. The variables chosen are those that are more prominent in the analysis performed so far. As shown in the figure, the uncertainty estimates

\footnotetext{
12 We also investigated the degree of association among the variable-specific uncertainty indexes by calculating the pairwise correlation coefficients between uncertainty shocks-i.e., after removing the mean and first-order persistence of each individual uncertainty series. The highest average pairwise correlation coefficient of one series with the remaining 23 is 0.29 .

13 Table 5 in "Appendix C" summarizes the degree to which these factors alter the forecasts. The first factor, $F_{t}$, is significant in 21 of the forecast regressions and encompasses the banking- and monetarysector variables, the non-oil international trade variables, real activity indexes, consumer confidence index, the government finances, and labor market variables. The second factor, $G_{t}$, is significant in 13 of the forecast regressions.
} 


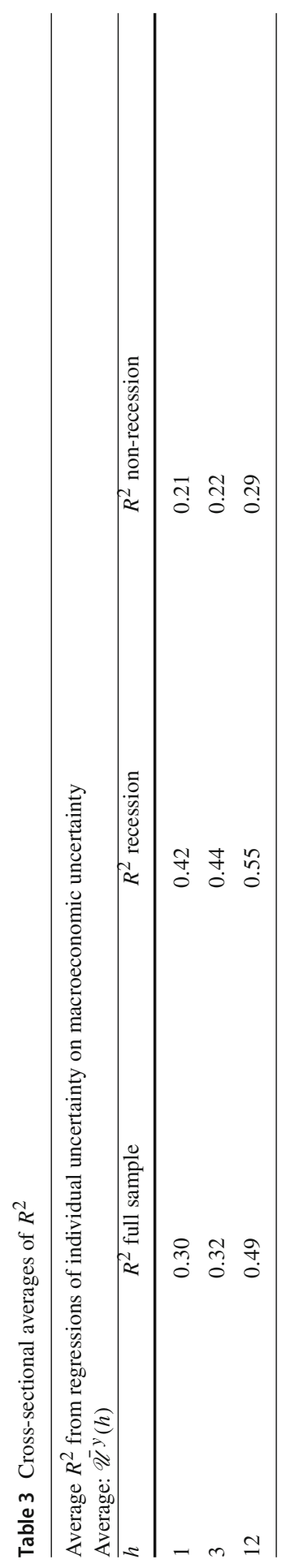



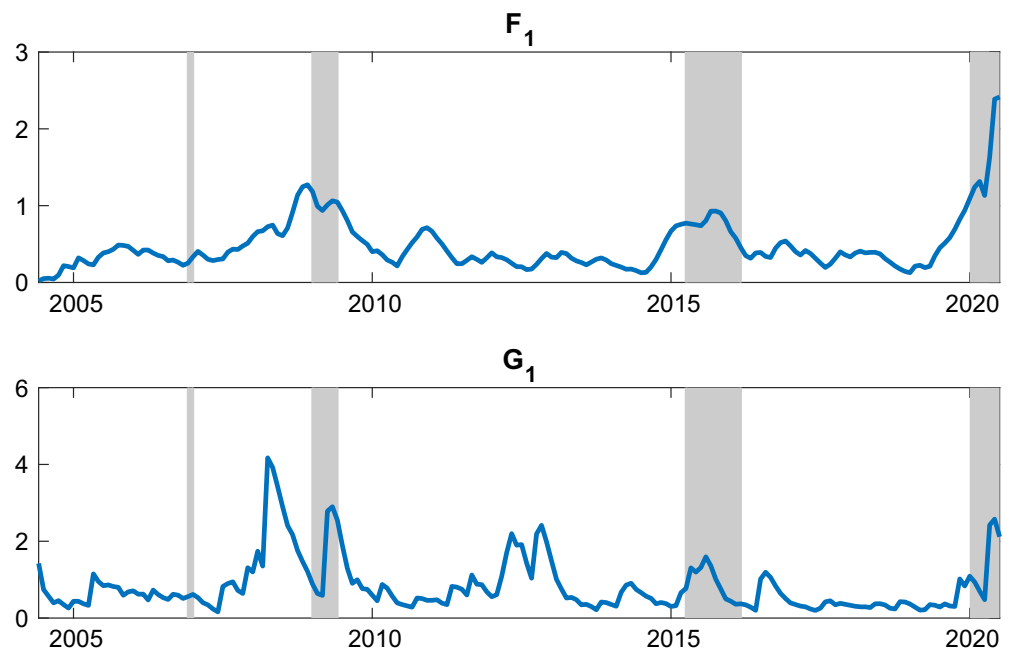

Fig. 3 Predictor uncertainty. Note: The uncertainty corresponds to $h=1$. Shaded areas correspond to recession periods defined as two or more consecutive quarters of declining GDP

in these series are significantly influenced by whether the forecastable variation is removed before computing the stochastic volatility models.

In general, we expect the vanilla model to produce a higher average uncertainty and order statistics than the baseline model. This difference is visible in the manufacturing and commercial activity indexes in the top panels in Fig. 4, in which the vanilla model has a higher uncertainty, on average, than the baseline model. The middle panels showcase the reduction in order statistics. In this case, the uncertainty spikes under the baseline model for oil production and value-added tax receipts are about onehalf and three-fourths, respectively, of those of the vanilla model. Finally, the bottom panels illustrate cases (for near money and consumer confidence) in which both the average uncertainties and the order statistics are smaller in the baseline model than in the vanilla specification. Hence, the specification with an autoregressive structure and factors does help to capture volatility in the forecast errors that otherwise would have been attributed to uncertainty.

We further examine how the one-period-ahead uncertainty would perform when allowing for the inclusion of the model's autoregressive components, but not the factors. This version of the model appears in Eq. (21):

$$
y_{j t}=\tilde{\phi}_{j}(L) y_{j, t-1}+\tilde{\sigma}_{j t} \tilde{u}_{j t} .
$$

We compare this model with the baseline model of Eq. (3) and the vanilla model in Eq. (20). Figure 5 shows a three-way comparison. As can be seen, the autoregressive components enable us to consider more available information about the economic outlook, compared with the vanilla model, to abstain from wrongly concluding that forecastable fluctuations are part of the uncertainty in the series. However, as the figure shows, the baseline model provides the lowest average level of uncertainty because the 

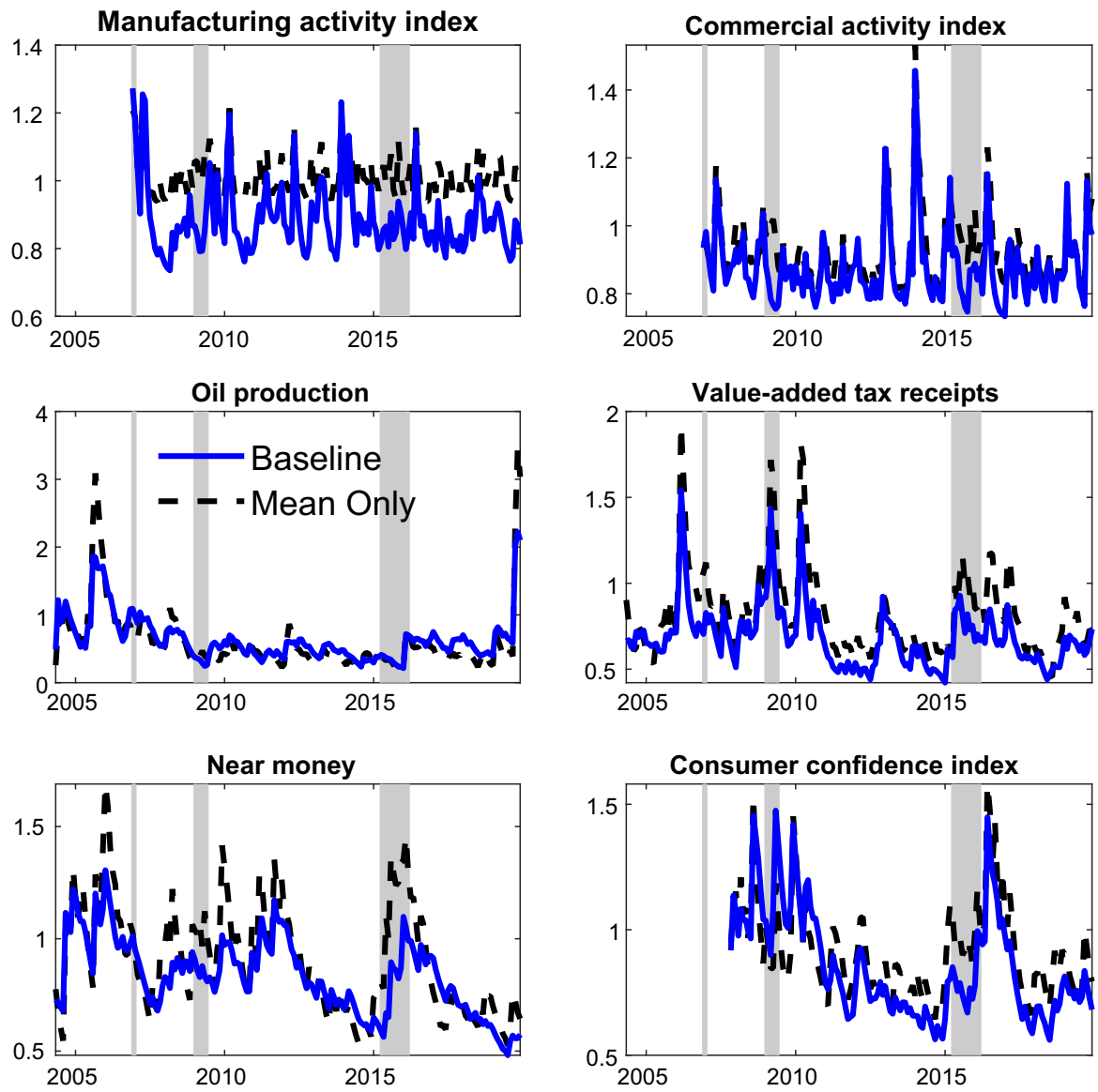

Fig. 4 Role of predictors. Note: The figures show the one-period-ahead uncertainty index for each variable in the baseline case (blue line) and in the case with no predictors (black dashed line). The sample corresponds to the baseline model's estimation that goes from 2004:M5 to 2019:M12. Shaded areas correspond to recession periods defined as two or more consecutive quarters of declining GDP

factors indeed help remove other forecastable fluctuations beyond the autoregressive structure, especially during recession periods.

\subsection{Sensitivity analysis: macroeconomic uncertainty index versus J.P. Morgan's Emerging Markets Bond Index}

An important analysis by JLN consists of comparing macroeconomic uncertainty and an indicator of stock market volatility, such as the VXO volatility index. ${ }^{14}$ In the context of the Ecuadorian economy, a measure of stock market volatility is not a representative indicator of uncertainty, as the capital markets are not well developed. In fact, the Guayaquil and Quito stock exchanges' trading volumes and market capitalization

\footnotetext{
14 This volatility index is constructed by the Chicago Board of Options Exchange from the prices of options contracts written on the S\&P 100 Index.
} 


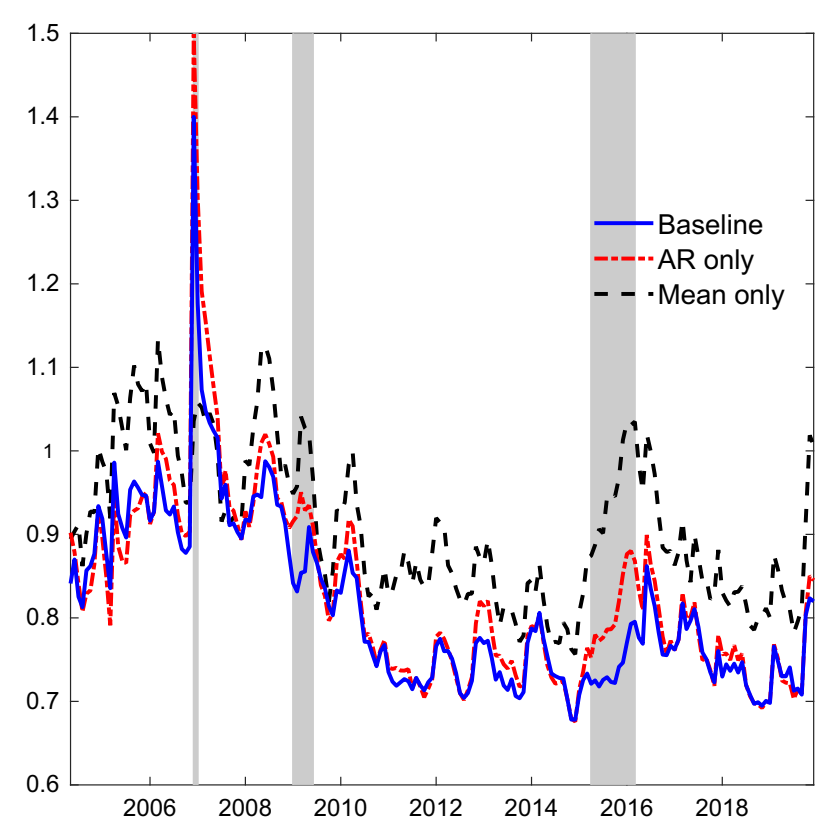

Fig. 5 Uncertainty under different specifications $(h=1)$. Note: The sample shown goes from 2004:M5 to 2019:M12. Shaded areas correspond to recession periods defined as two or more consecutive quarters of declining GDP

are small compared with those of other capital markets in the region. ${ }^{15}$ Thus, the J.P. Morgan Emerging Markets Bond Index for Ecuador (EMBI hereafter) is a more suitable variable explaining the level of country risk. The EMBI describes the country's capacity to repay its public debt and is sometimes used as a measure of uncertainty for the Ecuadorian economy.

Figure 6 plots the (standardized) EMBI for Ecuador as a proxy of uncertainty along with our (standardized) macroeconomic uncertainty index for $h=1$. The figure also includes a dashed horizontal line corresponding to 1.65 standard deviations above the mean for these normalized series. Because the EMBI is more focused on the fiscal sustainability of the country, one should expect the indexes to differ in their interpretation of macroeconomic uncertainty. Although both indexes exceed the threshold twice throughout the sample-in particular, during the recent recession triggered by the COVID-19 outbreak-our 1-month-ahead index exceeds the benchmark measure during the 2006-07 recession, while the EMBI surpasses it from early 2008 through mid-2009, during Ecuador's sovereign debt default and the subsequent recession, which our index interprets as a minor uptick in macroeconomic uncertainty only.

Although the indexes can show relevant differences during some periods, we note that they tend to move in the same direction, especially after the country's 2008 sovereign default. In fact, the contemporaneous correlation coefficient is 0.53 for the whole sample, increasing to 0.90 between October 2009 and June 2020.

\footnotetext{
$\overline{15}$ For instance, Ecuador's stock market capitalization represented $6.8 \%$ of its GDP in 2018, while this indicator in Chile reached $84 \%$ of its GDP.
} 


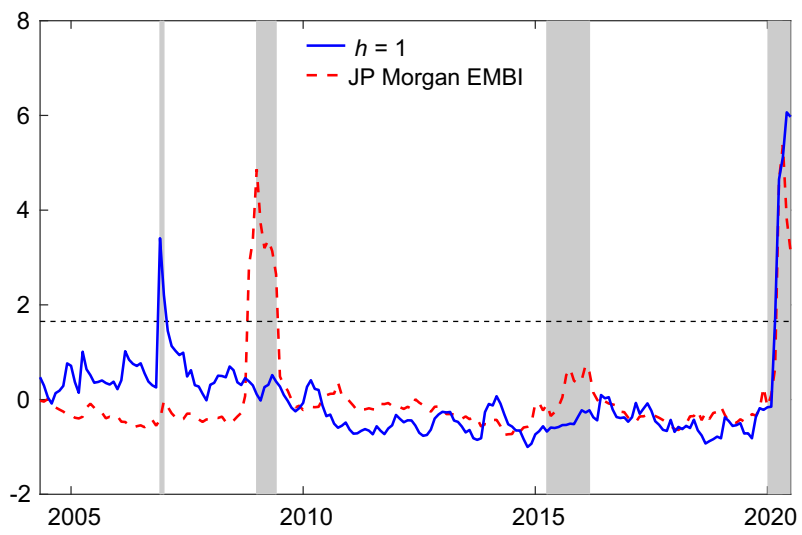

Fig. 6 Macroeconomic uncertainty index and JP Morgan EMBI. Note: Series are standardized. The horizontal line corresponds to 1.65 standard deviations above the mean of both series. Shaded areas correspond to recession periods defined as two or more consecutive quarters of declining GDP

\subsection{Uncertainty and macroeconomic dynamics}

Consistent with the results of JLN for the USA, our results for Ecuador point to interesting dynamic relationships between macroeconomic uncertainty and economic conditions. In particular, we show that uncertainty increases during recessions and that the explanatory power of aggregate macroeconomic uncertainty on its individual counterparts is higher in those times as well. In this section, we use structural vector autoregressions (SVARs) to estimate the dynamic responses of macroeconomic variables such as non-oil output, employment in the formal sector, and the consumer price index (CPI) to shocks in our uncertainty index for the three horizons. We also compute the responses to innovations in the EMBI as an alternative indicator of uncertainty.

Ludvigson et al. (forthcoming) find that increases in macroeconomic uncertainty are best characterized as an endogenous response to business cycle fluctuations. In particular, they note that negative shocks to economic activity cause increases in macroeconomic uncertainty, but there is little evidence that positive shocks to macroeconomic uncertainty play a large role in causing lower economic activity. They also find that an SVAR that includes macroeconomic uncertainty and output reflects a nonzero contemporaneous correlation between these two variables. Therefore, the validity of a recursive structure in which macroeconomic uncertainty is ordered first, as originally postulated by JLN, is easily rejected by the data. To account for endogeneity, the authors adopt so-called shock-based restrictions.

To deal with the potential endogeneity of our uncertainty index, we use an LP-IV approach (see Stock and Watson 2018; Plagborg-Møller and Wolf 2021). Our instrument is the volatility of the West Texas Intermediate (WTI) oil price posted for the Ecuadorian crude oil after premiums or penalties. Because Ecuador is a small oil exporter, fluctuations in oil prices (and their volatility) can be taken as exogenous 
contemporaneously as well as at any leads and lags. In addition, we conduct a search procedure to determine if the instrument should be lagged in order to fulfill the relevance condition. ${ }^{16}$

We use a monthly frequency from 2007:M1 to 2019:M12. ${ }^{17}$ Our VAR and local projections equations specify the uncertainty index along with the macroeconomic variables in log levels with three lags, linear trends on the macroeconomic variables, and we estimate them with classical methods. In addition, we perform a wild bootstrap using the residuals of the VAR model-augmented with an equation for the instrument with lagged feedback only from itself and without affecting the other variables of the system-to obtain the impulse response's confidence intervals.

Figure 7 shows the impulse-response functions of our VAR over 48 months for $h=1,3$, and 12 in the first three rows. In all cases, an increase in uncertainty of one standard deviation significantly reduces real GDP and formal employment below trend, whereas prices initially increase but eventually post-losses. These responses point to the detrimental effects of macroeconomic uncertainty. Additionally, the declines of GDP and employment are highly persistent, but the persistence of the CPI response is considerably lower. Moreover, the effect of uncertainty on GDP seems to be slightly stronger as the forecasting horizon lengthens.

The final row in Fig. 7 shows the responses of the macroeconomic variables when the EMBI is considered as a proxy for uncertainty, using the same instrumental variable as before. ${ }^{18}$ The responses are qualitatively similar to the shocks in macroeconomic uncertainty although a little less persistent in the case of output and employment; CPI seems to react more in the short run.

As we mentioned before, the EMBI is an indicator of the fiscal sustainability conditions of Ecuador, which can be fundamental for a dollarized economy. The effects of an increase in this index mimic well the effects of increased uncertainty on the macroeconomy. This feature indicates that in the case of a small oil exporter with the features of Ecuador, increases in the volatility of exogenous variables that trigger increases in uncertainty around fiscal sustainability, such as oil prices, could ultimately be the drivers of declines in economic activity due to higher macroeconomic uncertainty.

\section{Conclusions}

In this paper, we propose an alternative method to compute the macroeconomic uncertainty index originally put forward by JLN. Our method is easier to implement and can be more efficient than that of JLN. In addition, because it is more straightforward to

\footnotetext{
16 We obtain that macroeconomic uncertainty has a statistically significant correlation with the volatility of oil lagged 4 months at usual significance levels.

17 We construct a monthly estimate of non-oil GDP using the mixed-frequency approach of the nowcasting procedure proposed by González-Astudillo and Baquero (2019).

18 In this case, the contemporaneous volatility of oil prices has the highest correlation with the instrumented variable.
} 

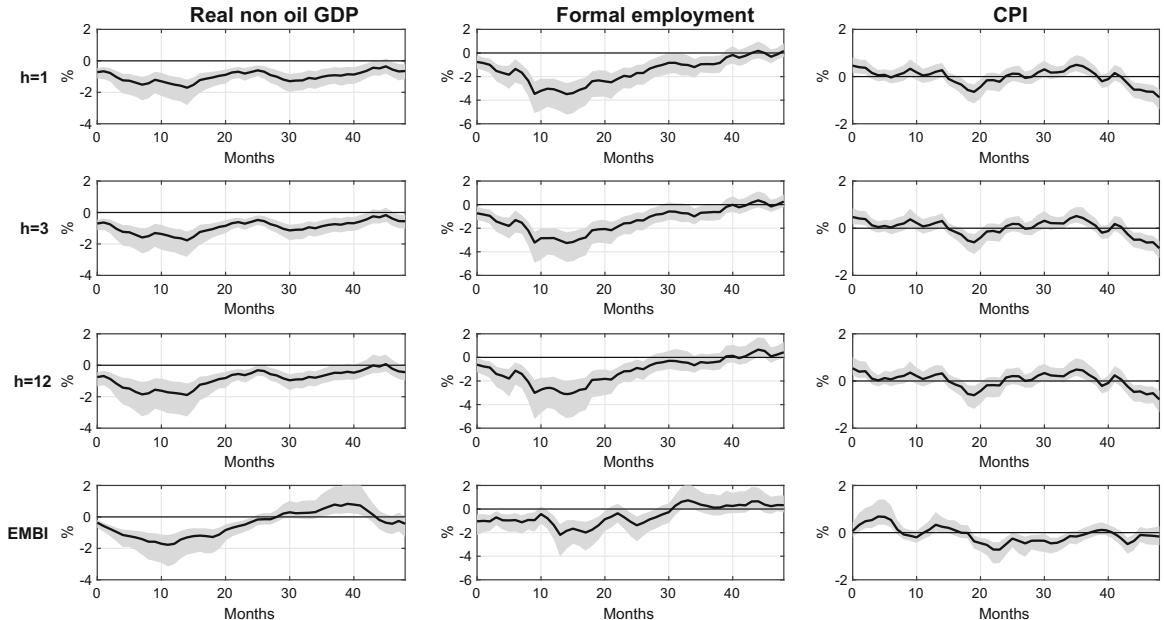

Fig. 7 Dynamic responses of real non-oil GDP, formal employment, and CPI to the macroeconomic uncertainty index and EMBI. Note: The shaded bands denote $68 \%$ confidence intervals

carry out, our method allows for a frequent update of the macroeconomic uncertainty index than can be useful for public and private decision-making. We show that our methodology produces a macroeconomic uncertainty index with very similar dynamics to that of JLN for the USA, although our method indicates a somewhat higher degree of uncertainty.

Our macroeconomic uncertainty index is the first estimate of this kind completed for a small developing or middle-income country. Ecuador's macroeconomic uncertainty index is composed of 24 macroeconomic variables covering the most relevant sectors of the economy. The index shows that uncertainty has declined, on average, over the past 10 years, but it started to increase at the end of 2019, reaching unprecedented levels during the COVID-19 pandemic. Our estimates indicate that the economy becomes more uncertain during recessions than otherwise. Moreover, we show through an SVAR model that the responses of key macroeconomic variables to uncertainty shocks are sizable and persistent.

Supplementary Information The online version contains supplementary material available at https://doi. org/10.1007/s00181-021-02069-5.

Acknowledgements This work was partially funded by Universidad Espíritu Santo, Samborondón, Ecuador.

\section{Declarations}

Conflict of interest The authors declare that they have no affiliations with or involvement in any organization or entity with any financial interest (such as honoraria; educational grants; participation in speakers' bureaus; membership, employment, consultancies, stock ownership, or other equity interest; and expert testimony or patent-licensing arrangements), or non-financial interest (such as personal or professional relationships, affiliations, knowledge or beliefs) in the subject matter or materials discussed in this manuscript. 


\section{Appendices}

\section{Appendix A: Sources of variables}

Table 4 Description of variables

\begin{tabular}{|c|c|c|c|c|}
\hline & & & Frequency & Source \\
\hline \multirow[t]{3}{*}{ Banking and monetary } & & Loans to expire & Monthly & $\mathrm{BCE}$ \\
\hline & & Near money & Monthly & $\mathrm{BCE}$ \\
\hline & & Demand deposits & Monthly & $\mathrm{BCE}$ \\
\hline \multirow[t]{7}{*}{ International trade } & Non-oil & Non-oil exports & Monthly & $\mathrm{BCE}$ \\
\hline & & Imports of capital goods & Monthly & $\mathrm{BCE}$ \\
\hline & & Imports of consumer goods & Monthly & $\mathrm{BCE}$ \\
\hline & & Imports of raw materials & Monthly & $\mathrm{BCE}$ \\
\hline & Oil & Oil exports & Monthly & $\mathrm{BCE}$ \\
\hline & & Imports of fuels and lubricants & Monthly & $\mathrm{BCE}$ \\
\hline & & Oil production & Monthly & $\mathrm{BCE}$ \\
\hline \multirow[t]{4}{*}{ Indexes } & Confidence & Consumer confidence index & Monthly & INEC \\
\hline & Prices & $\mathrm{CPI}$ & Monthly & INEC \\
\hline & & CPI w/o food and energy & Monthly & INEC \\
\hline & & PPI & Monthly & INEC \\
\hline \multirow[t]{4}{*}{ Real activity indexes } & & Manufacturing & Monthly & $\mathrm{BCE}$ \\
\hline & & Commerce & Monthly & $\mathrm{BCE}$ \\
\hline & & Construction & Monthly & $\mathrm{BCE}$ \\
\hline & & Services & Monthly & $\mathrm{BCE}$ \\
\hline \multirow[t]{2}{*}{ Government finances } & & Value-added tax receipts & Monthly & SRI \\
\hline & & Income tax receipts & Monthly & SRI \\
\hline \multirow[t]{4}{*}{ Labor market indexes } & & Manufacturing & Monthly & $\mathrm{BCE}$ \\
\hline & & Commerce & Monthly & $\mathrm{BCE}$ \\
\hline & & Construction & Monthly & $\mathrm{BCE}$ \\
\hline & & Services & Monthly & $\mathrm{BCE}$ \\
\hline
\end{tabular}

INEC National Institute of Statistics and Census, BCE Central Bank of Ecuador, SRI Internal Revenue Service, $C P I$ consumer price index, $P P I$ producer price index

In the banking and monetary data set, we include 3 variables: (a) loans-to-expire to the private sector, (b) near money (M2), and (c) demand deposits. These variables are published monthly by the BCE.

The international trade category clusters seven variables: (a) non-oil exports, (b) oil exports, (c) imports of capital goods, (d) imports of fuels and lubricants, (e) imports of consumer goods, (f) imports of raw materials, and (g) oil production.

The prices and confidence indexes include the following variables: (i) consumer price index (CPI), (ii) CPI without food and energy, (iii) producer price index (PPI), and (iv) consumer confidence measured by the Current Situation Index. 
The variables included in the sectoral indexes group come from the Monthly Business Opinion Surveys developed by the BCE. These variables are based on the response of 1000 large firms regarding the next month expectations of production, construction volumes and sales. The variables refer to the following sectors: (i) commerce, (ii) construction, (iii) manufacturing, and (iv) services.

The government finances category includes two variables: (i) value-added tax receipts and (ii) income tax receipts (monthly collections). These two items combined have represented, on average, $64-68 \%$ of the government's annual tax revenue for the years 2006-2018.

As the sectoral indexes, the employment indexes come from the Monthly Business Opinion Surveys developed by the BCE. The survey summarizes individual firms changes to employed personnel on a monthly basis. The variables refer to the following sectors: (i) commerce, (ii) construction, (iii) manufacturing, and (iv) services (Table 4).

\section{Appendix B: Density filter}

In Eqs. (15)-(18), the following holds:

$$
\begin{aligned}
p\left(z_{t} \mid z_{t-1}\right) & =\frac{1}{\sqrt{2 \pi\left(1-\rho^{2}\right)}} \exp \left(-\frac{1}{2} \frac{\left(z_{t}-\rho z_{t-1}\right)^{2}}{\left(1-\rho^{2}\right)}\right), \\
p\left(v_{t} \mid z_{t}\right) & =\frac{1}{\sqrt{2 \pi \exp \left(\alpha_{0}+\alpha_{1} z_{t}\right)}} \exp \left(-\frac{1}{2} \frac{v_{t}^{2}}{\exp \left(\alpha_{0}+\alpha_{1} z_{t}\right)}\right) .
\end{aligned}
$$

In particular, we use $p_{1}$, an $m \times 1$ vector, to denote the prediction step density, $p\left(z_{t} \mid F_{t-1}\right)$, and $p_{0}$, also an $m \times 1$ vector, to denote the updating step density, $p\left(z_{t} \mid F_{t}\right)$. We can approximate the filtered state, $E\left(z_{t} \mid F_{t}\right)$, by $\sum_{j=1}^{m} z_{j} p_{0}[j]$.

The filter works as follows:

- input $v_{T \times 1}, \theta_{p \times 1}, m_{1 \times 1}, z_{01 \times 1}, h_{1 \times 1}$

- output $l_{1 \times 1}$

- Initialization

$-z_{0}$

$-z, w$ Gauss-Legendre quadrature nodes and weights in $\left(z_{0}-h, z_{0}+h\right)$

- $p_{0}[i]=w_{i} p_{0}\left(z_{i}\right) / w\left(z_{i}\right)$ with $p_{0}(\cdot)$ being the standard normal density

$-l=0$

- for $t=1$ to $T$

- $p_{1}[i]=\sum_{j=1}^{m} p\left(z_{i} \mid z_{j}\right) p_{0}[j], \quad 1, \ldots, m$

- $p_{0}[i]=p\left(v_{t} \mid z_{i}\right) w_{i} p_{1}[i] / w\left(z_{i}\right), \quad 1, \ldots, m$

$-c_{t}=\sum_{j=1}^{m} p_{0}[j]$

$-p_{0}[i]=p_{0}[i] / c_{t}, \quad 1, \ldots, m$

$-l=l+\ln \left(c_{t}\right)$

- end for 
We choose $m=20, z_{0}=0$ and $h=5$. Choosing more nodes or a wider interval do not change the results significantly.

\section{Appendix C: Additional results}

See Table 5.

Table 5 Additional results

\begin{tabular}{|c|c|c|c|c|c|c|}
\hline \multirow{2}{*}{\multicolumn{2}{|c|}{ Variable categories }} & \multirow[t]{2}{*}{ Variables } & \multirow{2}{*}{$\begin{array}{l}\text { Baseline } \\
R^{2}\end{array}$} & \multicolumn{2}{|c|}{ Factors } & \multirow{2}{*}{$\overline{\mathscr{U}}_{j}^{y}(1)$} \\
\hline & & & & $\overline{F_{t}}$ & $G_{t}$ & \\
\hline \multirow{3}{*}{\multicolumn{2}{|c|}{ Banking and monetary }} & Loans to expire & 0.744 & $* * *$ & $* *$ & 0.659 \\
\hline & & Near money & 0.552 & $* * *$ & & 0.859 \\
\hline & & Demand deposits & 0.341 & $* * *$ & & 0.943 \\
\hline \multirow[t]{7}{*}{ International trade } & Non-Oil & Non-oil exports & 0.380 & & & 0.801 \\
\hline & & Imports of capital goods & 0.554 & $* * *$ & & 0.820 \\
\hline & & Imports of consumer goods & 0.445 & $* * *$ & $* *$ & 0.839 \\
\hline & & Imports of raw materials & 0.687 & $* * *$ & & 0.795 \\
\hline & Oil & Oil exports & 0.218 & & & 0.770 \\
\hline & & Imports of fuels and lubricants & 0.477 & $* *$ & & 0.744 \\
\hline & & Oil production & 0.604 & & & 0.350 \\
\hline \multirow[t]{4}{*}{ Indexes } & Confidence & Consumer confidence index & 0.153 & $* * *$ & $* *$ & 0.864 \\
\hline & Prices & CPI & 0.717 & $* * *$ & $* * *$ & 0.811 \\
\hline & & CPI w/o food and energy & 0.618 & $* *$ & $* * *$ & 0.713 \\
\hline & & PPI & 0.553 & $* *$ & $* *$ & 0.833 \\
\hline \multirow{4}{*}{\multicolumn{2}{|c|}{ Real activity indexes }} & Manufacturing & 0.434 & $* * *$ & & 0.726 \\
\hline & & Commerce & 0.194 & $* * *$ & $* *$ & 0.593 \\
\hline & & Construction & 0.572 & $* * *$ & $*$ & 0.787 \\
\hline & & Services & 0.145 & $*$ & $*$ & 0.661 \\
\hline \multirow{2}{*}{\multicolumn{2}{|c|}{ Government finances }} & Value-added tax receipts & 0.637 & $* * *$ & $*$ & 0.716 \\
\hline & & Income tax receipts & 0.785 & $* *$ & & 0.733 \\
\hline \multirow{4}{*}{\multicolumn{2}{|c|}{ Labor market indexes }} & Manufacturing & 0.256 & $* * *$ & & 0.845 \\
\hline & & Commerce & 0.432 & $* * *$ & $* *$ & 0.732 \\
\hline & & Construction & 0.612 & $* * *$ & $* *$ & 0.754 \\
\hline & & Services & 0.456 & $* * *$ & $* *$ & 0.792 \\
\hline
\end{tabular}

The first three columns correspond to equation 3. The first column is the adjusted $R^{2}$ of the regression, while the factor columns correspond to the factor significance in the model. Note that *** represents $1 \%$ significance level; **5\% significance level; and * 10\% significance level. The fourth column correspond to the individual series uncertainty, Eq. 14, averaged over time 


\section{References}

Bai J, Ng S (2002) Determining the number of factors in approximate factor models. Econometrica 70(1):191-221. https://doi.org/10.1111/1468-0262.00273

Baker S, Bloom N, Davis S (2016) Measuring economic policy uncertainty. Q J Econ 131(4):1593-1636

Banbura M, Modugno M (2014) Maximum likelihood estimation of factor models on data sets with arbitrary pattern of missing data. J Appl Econom 29(1):133-160

Banbura M, Giannone D, Reichlin L (2010) Nowcasting

Cattell R (1966) The scree test for the number of factors. Multivar Behav Res 1:245-276

Friedman M, Harris L (1998) A maximum likelihood approach for non-Gaussian stochastic volatility models. J Bus Econ Stat 16(3):284-91

García-Albán F, González-Astudillo M, Vera-Avellán C (forthcoming) Good policy or good luck? Analyzing the effects of fiscal policy and oil revenue shocks in Ecuador. Energy Econ 105321. https://doi.org/ 10.1016/j.eneco.2021.105321

Giannone D, Reichlin L, Small D (2008) Nowcasting: the real-time informational content of macroeconomic data. J Monet Econ 55(4):665-676

Giannone D, Reichlin L, Banbura M (2010) Nowcasting, No 1275, Working paper series, European Central Bank

Godeiro L, Lima LR (2017) Measuring macroeconomic uncertainty to Brasil. Econ Apl 21(2):311-334. https://doi.org/10.11606/1413-8050/ea156958

González-Astudillo M, Baquero D (2019) A nowcasting model for Ecuador: implementing a time-varying mean output growth. Econ Modell. https://doi.org/10.1016/j.econmod.2019.01.010

Grimme C, Stöckli M (2018) Measuring macroeconomic uncertainty in Germany. CESifo Forum 19(1):4650

Huang Z, Tong C, Qiu H, Shen Y (2018) The spillover of macroeconomic uncertainty between the U.S. and China. Econ Lett 171:123-127. https://doi.org/10.1016/j.econlet.2018.07.018

Jurado K, Ludvigson S, Ng S (2015) Measuring uncertainty. Am Econ Rev 105(3):1177-1216

Kawakatsu H (2007) Numerical integration-based Gaussian mixture filters for maximum likelihood estimation of asymmetric stochastic volatility models. Econom J 10(2007):342-358. https://doi.org/10. 1111/j.1368-423X.2007.00211.X

Ludvigson S, Ma S, Ng S (forthcoming) Uncertainty and business cycles: exogenous impulse or endogenous response? Am Econ J Macroecon. https://www.aeaweb.org/articles?id=10.1257/mac.20190171

Padilla S (2019) Índice de incertidumbre de política económica para Ecuador: discusiones y una propuesta de cuantificación. REVISTA PUCE 108:177-211

Plagborg-Møller M, Wolf CK (2021) Local projections and vars estimate the same impulse responses. Econometrica 89(2):955-980

Shin M, Zhang B, Zhong M, Lee DJ (2018) Measuring international uncertainty: the case of Korea. Econ Lett 162:22-26. https://doi.org/10.1016/j.econlet.2017.10.014

Stock JH, Watson M (2018) Identification and estimation of dynamic causal effects in macroeconomics using external instruments. Econ J 128(610):917-948

Watson M, Engle R (1983) Alternative algorithms for the estimation of dynamic factor, mimic and varying coefficient regression models. J Econ 23(3):385-400

World Bank Group (2018) Ecuador systematic country diagnostic. World Bank, Washington, DC. (C) World Bank. https://openknowledge.worldbank.org/handle/10986/30052. License: CC BY 3.0 IGO

Publisher's Note Springer Nature remains neutral with regard to jurisdictional claims in published maps and institutional affiliations. 